\title{
First high-power model of the annular-ring coupled structure for use in the Japan Proton Accelerator Research Complex linac
}

\author{
Hiroyuki $\mathrm{Ao}^{*}$ and Yoshishige Yamazaki \\ J-PARC Center, Japan Atomic Energy Agency, 2-4 Shirakata-shirane, Tokai, Naka, Ibaraki 319-1195, Japan
}

(Received 12 September 2011; published 10 January 2012)

\begin{abstract}
A prototype cavity for the annular-ring coupled structure (ACS) for use in the Japan Proton Accelerator Research Complex (J-PARC) linac has been developed to confirm the feasibility of achieving the required performance. This prototype cavity is a buncher module, which includes ten accelerating cells in total. The ACS cavity is formed by the silver brazing of ACS half-cell pieces stacked in a vacuum furnace. The accelerating cell of the ACS is surrounded by a coupling cell. We, therefore, tuned the frequencies of the accelerating and coupling cells by an ultraprecision lathe before brazing, taking into account the frequency shift due to brazing. The prototype buncher module was successfully conditioned up to $600 \mathrm{~kW}$, which corresponds to an accelerating field that is higher than the designed field of $4.1 \mathrm{MV} / \mathrm{m}$ by $30 \%$. We describe the frequency-tuning results for the prototype buncher module and its high-power conditioning.
\end{abstract}

DOI: 10.1103/PhysRevSTAB.15.011001

PACS numbers: 29.20.Ej

\section{INTRODUCTION}

Several types of biperiodic (alternating periodic) $\pi / 2$-mode structures [1] have been developed for roomtemperature high-energy proton linacs: an on-axis coupled structure [2], a side-coupled structure (SCS) [3], a diskand-washer structure [4], and an annular-ring coupled structure (ACS) [4].

Geometrically, the ACS can be considered as an axially symmetric version of the SCS. One example of the ACS is shown in Figs. 1-3. In terms of multiplicity, the SCS shows dipole asymmetry, while the ACS with four coupling slots [5] shows octupole asymmetry. The accelerating field at the axis of the SCS has a dipole component of approximately one percent, whereas that at the axis of the ACS has a negligibly small octupole component [5].

The elimination of beam loss is one of the most important issues for high-intensity proton accelerators. So far, the beam losses arising from the axially asymmetric field of the SCS have not been reported in either SNS or LAMPF. However, the asymmetry possibly gives rise to emittance growth and/or halo formation, which has not been fully studied, partly because of a lack of experimental data. Under this circumstance, it is preferable to improve the axial symmetry of the accelerating field, if it can be done without any cost.

In fact, the shunt impedance and coupling factor of the ACS are comparable to those of the SCS [1]. However, because of the axial symmetry, the ACS has the following advantages over the SCS (see Figs. 1-3): (i) The whole

\footnotetext{
*hiroyuki.ao@j-parc.jp

Published by the American Physical Society under the terms of the Creative Commons Attribution 3.0 License. Further distribution of this work must maintain attribution to the author(s) and the published article's title, journal citation, and DOI.
}

structure except the coupling slots can be machined by an ultraprecision turning machine (lathe). (ii) It is possible to measure the frequency of the coupling cells before brazing by stacking two half-cell pieces, as detailed in Sec. III. (iii) The cylindrical outer shape, which has no extension such as a coupling cell of the SCS, has high mechanical stiffness during silver brazing $(28 \% \mathrm{Cu}$ and $72 \% \mathrm{Ag})$ in a high-temperature vacuum furnace, installation and/or transportation, and high-power operations. (iv) The thermal expansion is axially symmetric during high-power operations. The local concentration of mechanical stress is much lower than that in the case of asymmetric structures.

The smooth surface of the ACS obtained by ultraprecision machining guarantees a high $Q$ value and high discharge limit. In particular, the latter is important for realizing a stable operation as well as short conditioning

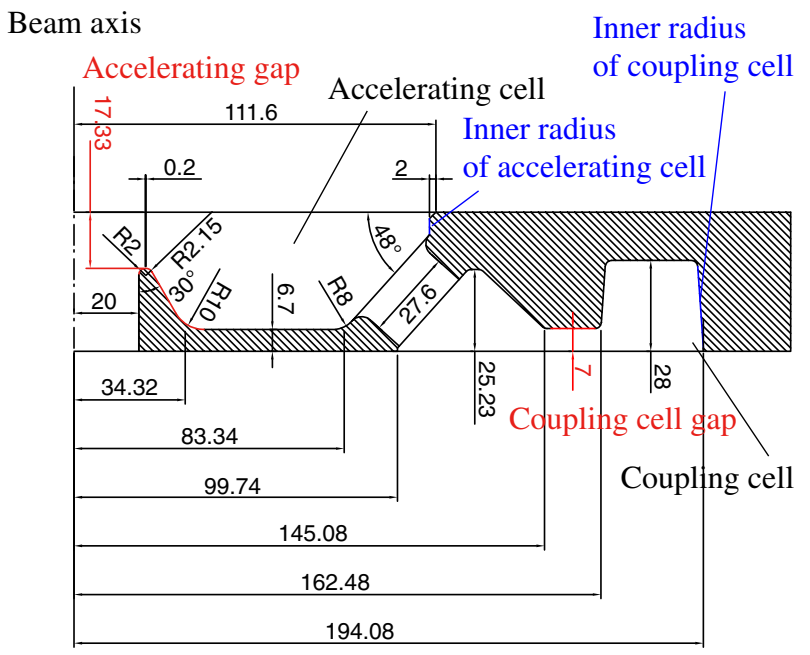

FIG. 1. Cell geometry of the ACS debuncher (unit: mm). 


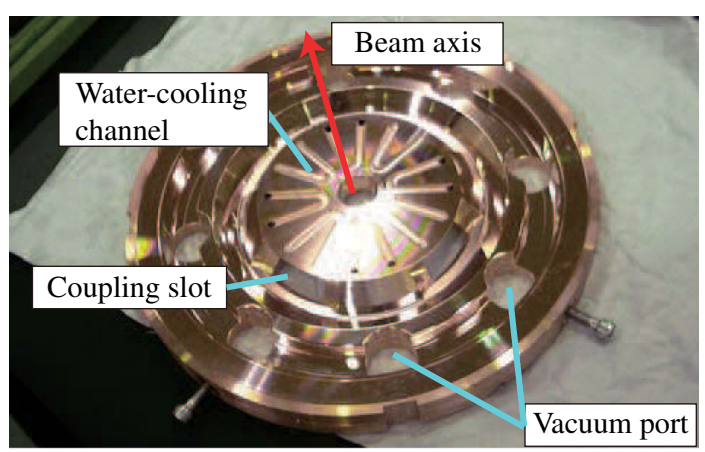

FIG. 2. Half-cell piece of the ACS as viewed from the coupling-cell side (see Fig. 4).

time. These are the main reasons for our developing an ACS for the Japan Proton Accelerator Research Complex (J-PARC) [6] linac.

On the other hand, it is difficult to tune the acceleratingcell frequency of the ACS after assembling, which is in contrast to the case of SCS. The accelerating-cell frequency of the SCS can be tuned by deforming the structure from the outside, whereas that of the ACS is surrounded by its coupling cell. Therefore, we have to use different methods for tuning the ACS.

It should be noted that the ACS can be precisely machined by using an ultraprecision lathe. The cell frequency can be tuned by machining the cell, taking into account the frequency shift due to brazing, as long as the shift is reproducible. In this case, the machining process may include frequency measurement and corrective machining. Therefore, reproducibility is a key factor for achieving this tunability. The present report will partly include the test results on reproducibility.

For use in the J-PARC linac, the cavity design of the ACS was significantly improved on the basis of a JHP (Japan Hadron Project [7]) ACS [5]. Since the operating frequency of the J-PARC ACS $(972 \mathrm{MHz})$ is different from that of the JHP ACS (1296 MHz), the J-PARC ACS would become too big and too heavy to manage if it is scaled up from the JHP ACS. For this reason, the effort [8] was concentrated on reducing the dimensions of the J-PARC ACS, while retaining all the advantages of the JHP ACS.

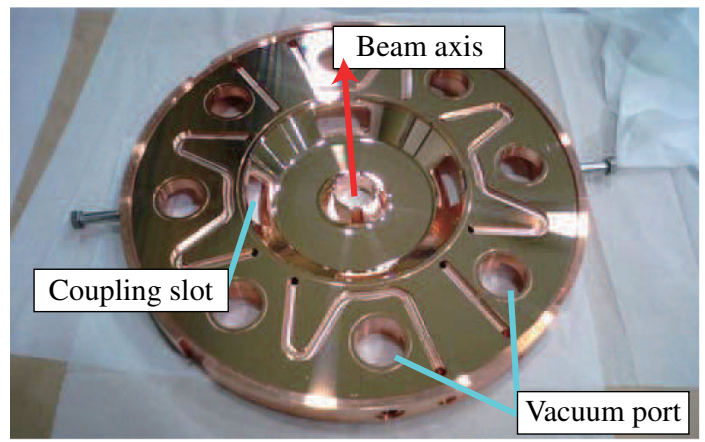

FIG. 3. Half-cell piece of the ACS as viewed from the accelerating-cell side (see Fig. 4).
As a result, the designs of the coupling slots, coupling cells, and other components of the J-PARC ACS were significantly modified, as can be observed in Figs. 1-3 and Ref. [8] (as detailed in Sec. III A 1). However, the basic features of both the JHP and J-PARC ACSs are common. The new ACS is easy to machine and is thus suitable for mass production. Hand finishing was eliminated by using a five-axis machining center.

In the next step, it was planned to fabricate and test an ACS prototype cavity for confirming the feasibility of achieving the performance required for this newly designed ACS. In particular, it is vital to power a structure when choosing it for such a big project as J-PARC. For example, it is necessary to study the influence of multipactoring in the coupling cells. Needless to say, the experience obtained during the development of the 1296-MHz JHP ACS was fully utilized for the fabrication of the J-PARC ACS. This report describes the fabrication of the ACS prototype cavity and the results of a high-power test of this cavity for using it in the J-PARC linac.

\section{CONFIGURATION OF THE J-PARC ACS AND ITS PROTOTYPING}

One ACS "module" consists of two accelerating tanks and one bridge tank (see Fig. 4). At the center of the bridge tank, a waveguide is connected to the module for providing rf power. Adjustable tuning plungers are attached to the excited cells of the bridge tank. Vacuum manifolds are installed at the ends of the accelerating tanks. The module is evacuated through these manifolds by using two ion pumps.

One accelerating tank (full size) comprises 17 accelerating and 16 coupling cells. One bridge tank consists of nine cells (five accelerating-cell equivalents and four

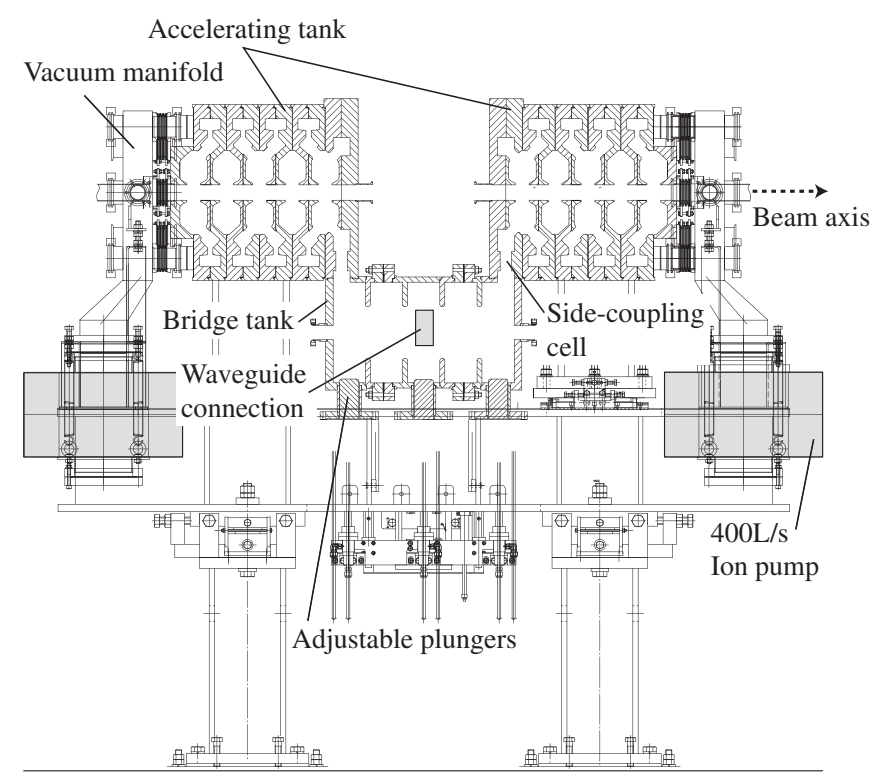

FIG. 4. Configuration of the ACS buncher module. 
coupling-cell equivalents). The accelerating and bridge tanks are connected by a side-coupling cell between these tanks. Twenty-one ACS modules in total accelerate $\mathrm{H}^{-}$ beams from 190 to $400 \mathrm{MeV}$. They are thus referred to as the ACS-accelerating modules. In addition to these 21 ACS-accelerating modules, four ACS modules are used for longitudinal matching: two for bunching at the upstream of the 21 ACS-accelerating modules and two for debunching at the downstream. Table I lists the number of the accelerating and coupling cells for these ACS modules.

The main parameters and schematic drawings of the ACS buncher module are shown in Table II and Fig. 4, respectively. The ACS buncher module is the minimum system required for including the second nearest neighbor coupling between the normal coupling cells. Therefore, tests to examine the following were performed on this module functioning as the ACS prototype cavity: (i) fabrication (vacuum-tight brazing) and frequency tuning; (ii) frequency shift due to brazing; (iii) accelerating field is as designed or not; (iv) heat loading and cooling capacity are as designed or not; (v) thermal detuning is as designed or not; (vi) outgas and vacuum pressure; and (vii) partial test for robustness against multipactor.

The performance of the ACS-accelerating module cannot be estimated by extrapolating that of the prototype based only on the tests for examining items (ii) and (vii) listed above. Item (ii) may depend upon the number of cells, since the difference in weight loading may influence the deformation of a structure during its silver brazing $(28 \% \mathrm{Cu}$ and $72 \% \mathrm{Ag})$. In addition, the temperature distribution, which depends upon the number of cells, may influence the deformation. In the case of item (vii), the longer accelerating tank increases not only the maximum excited field of the coupling cell but also the spread of the excited power among the coupling cells, thus enhancing

TABLE I. The number of accelerating and coupling cells, and the required number of modules. AC and CC stand for accelerating cell and coupling cell, respectively.

\begin{tabular}{lrrrrr}
\hline \hline & \multicolumn{2}{c}{ Accelerating tank } & \multicolumn{2}{c}{ Bridge tank } & \multirow{2}{*}{ Required } \\
Module & AC & CC & AC & CC & modules \\
\hline Accelerating & 17 & 16 & 5 & 4 & 21 \\
Buncher & 5 & 4 & 3 & 2 & 2 \\
Debuncher 1 & 6 & 5 & 3 & 2 & 1 \\
Debuncher 2 & 9 & 8 & 3 & 2 & 1 \\
\hline \hline
\end{tabular}

TABLE II. Main parameters for the ACS buncher module.

\begin{tabular}{lc}
\hline \hline Frequency & $972 \mathrm{MHz}$ \\
$\beta$ & 0.556 \\
Accelerating field E0 & $4.1 \mathrm{MV} / \mathrm{m}$ \\
Accelerating tank length (two tanks total) & $0.857 \mathrm{~m}$ \\
Repetition & $50 \mathrm{~Hz}$ \\
Pulse length & $600 \mu \mathrm{s}$ \\
\hline \hline
\end{tabular}

the risk of the multipactoring. Nevertheless, on the basis of these tests, the performance of the ACS-accelerating module can be estimated to some extent, if the extrapolation is performed carefully.

\section{FABRICATION PROCESS}

\section{A. Initial design}

\section{Bore radius, nose cone, and coupling slot}

Since the frequency of the J-PARC ACS is three-fourths that of the JHP ACS, the size of the former should be fourthird that of the latter, if scaled. In order to reduce the size of the coupling cell, its capacitance was increased by decreasing the length of the coupling-cell gap. Moreover, the coupling cell was shaped to ensure tool accessibility for machining the coupling slot (see Ref. [8] in detail). As a result, the coupling cell for the J-PARC ACS was significantly modified from that for the JHP ACS. Figure 2 shows an ACS half-cell piece as viewed from the coupling-cell side.

In addition, the accelerating cell was revised as follows. A bore radius of $20 \mathrm{~mm}$ was chosen to fulfill the beamdynamics requirement. Rather large inner and outer radii of 2 and $2.15 \mathrm{~mm}$, respectively, were chosen for the nose cone for keeping the maximum surface electric field within the Kilpatrick limit $E_{k}$. Moreover, a large nose-cone angle of $30^{\circ}$ was chosen for reducing the temperature difference between the nose tip and water-cooling channel. Here, it should be noted that a high-duty operation, typically up to $15 \%$, is predicted for the future possible upgrade projects.

A part of the inner surface of the accelerating cell was shaped as a straight oblique line rather than a rounded curve in order to simplify and ease the machining of the coupling slot between the accelerating and coupling cells. A slot height of $27.6 \mathrm{~mm}$ and a slot-opening angle of $33^{\circ}$ were chosen to obtain a coupling factor as high as $6 \%$. It should be noted that all the above-mentioned choices decreases the shunt impedance as a trade-off. Figure 3 shows the ACS half-cell piece as viewed from the accelerating-cell side.

\section{Frequency-tuning procedure}

The required accuracies for the frequency tuning are listed in Table III. The corresponding machining accuracies are also listed in this table. Since the resonant frequency during operation is adjusted with tuning plungers, the accelerating frequency has to be tuned within the adjustable limits of $\pm 0.5 \mathrm{MHz}$ during fabrication. The coupling-cell tuning should be sufficient to achieve the required uniformity of $1 \%$ for the field flatness. The accuracy was determined by a coupled resonator model for an accelerating module (see Appendix A).

Unfortunately, the prediction of the cell frequencies with the coupling slots by using the $3 \mathrm{D}$ electromagnetic simulation code MAFIA was not sufficiently accurate for the 
TABLE III. Required accuracies for the frequency tuning.

\begin{tabular}{lc}
\hline \hline Resonant frequency & $972 \mathrm{MHz}$ \\
Tuning limits of the adjustable tuning plunger & $\pm 0.5 \mathrm{MHz}$ \\
Target accuracies for the frequency tuning & \\
Accelerating cell & $\pm 0.1 \mathrm{MHz}$ \\
Coupling cell & $\pm 0.1 \mathrm{MHz}$ \\
Machining accuracy corresponding to $\pm 0.1 \mathrm{MHz}$ & \\
Accelerating gap $^{\mathrm{b}}$ & $\pm 7 \mu \mathrm{m}$ \\
Coupling-cell gap $^{\mathrm{b}}$ & $\pm 3 \mu \mathrm{m}$ \\
\hline \hline
\end{tabular}

${ }^{\mathrm{a}}$ See Appendix A for detailed comments.

${ }^{\mathrm{b}} \mathrm{See}$ the red-colored parts shown in Fig. 1

present purpose. Therefore, MAFIA was used only to estimate the difference between the frequencies with and without the coupling slots and this difference was added to the SUPERFISH-calculated value. The accuracy was significantly improved, being useful in some cases, but was still not enough. This method was used only to start the process, i.e., to determine the cell parameters for the two prototype half-cell pieces. Their frequencies were measured and the difference between the frequencies with and without the coupling slots was evaluated as the difference between the measured value (the frequency with the coupling slots) and the SUPERFISH-calculated value (the frequency without the coupling slots). By considering this frequency difference, SUPERFISH was used to adjust the gap size for tuning the accelerating cell (to $972 \mathrm{MHz}$ plus a margin of the final frequency tuning). For the coupling-cell tuning, the inner radius of the coupling cell (see Fig. 1) was adjusted.

\section{B. Machining and frequency tuning}

The ACS-accelerating tank is formed by silver brazing the half-cell pieces stacked in a vacuum furnace. Before brazing, all the half-cell pieces are machined and tuned by an ultraprecision lathe. While the inner radius can be machined with a sufficient accuracy, the accelerating-gap size (and maybe others) is hard to obtain with a sufficient accuracy. In order to overcome this difficulty, we chose a tuning method described in the following steps: (i) After rough machining, the coupling slots and water-cooling channels are grooved and the vacuum ports are drilled by a five-axis machining center, while the axially symmetric machining is performed by a commonly used lathe. (ii) An ultraprecision lathe is then used for precise, axially symmetric machining, but a small volume is left for the final machining of the inner radius. (iii) At this point, both the accelerating and coupling-cell frequencies are measured by pressing the two half cells together. Here, the frequencies are measured at various contact pressures. The reliability of this measurement is confirmed from the approximate linearity of the frequency variations with the pressures. The values linearly extrapolated to the zero contact pressure are used as the correct frequencies. (iv) The final machining of the inner radius of the accelerating and coupling cells (see Fig. 1) is performed for the precise tuning of the frequency. Before this machining, we require the coefficient $d f / d r$, where $f$ and $r$ are the resonant frequency and radius, respectively. The machining of the inner radius was thus performed in at least two steps to measure $d f / d r$.

\section{Frequency-tuning results and frequency shift due to brazing \\ 1. Designed frequency before brazing}

In order to obtain an operating frequency of $972 \mathrm{MHz}$, the frequency tunings before the brazing were aimed at 971.94 and $971.30 \mathrm{MHz}$ for the accelerating and coupling modes, respectively. These values were chosen by taking into account the frequency shift due to the silver brazing and thermal detuning during the high-power operation. Although the values of the frequency shift due to the brazing should have been obtained by the full-length cavity fabrication, as previously mentioned, we took into account the frequency shift due to the brazing partly by using the result of a test brazing of two half-cell pieces in order to avoid any excessive-frequency error. Table IV lists the result of the test brazing. It can be seen from Table IV that the accelerating-cell and coupling-cell frequencies increased by 0.10 and $0.71 \mathrm{MHz}$, respectively, during the test brazing process. The frequency measurements were performed as shown in Fig. 5. On the other hand, the thermal detuning during the high-power operation was evaluated by using ANSYS, which is detailed in Ref. [9]. As the results of this analysis, under the high-power operation, the accelerating-cell frequency decreased by $0.04 \mathrm{MHz}$, while the change in the coupling-cell frequency was negligible.

\section{Frequency-tuning results before brazing}

The normal cell frequencies are listed in Table V, which shows a comparison of the tuned frequencies with the designed ones. It can be seen from Table $\mathrm{V}$ that the

TABLE IV. Frequency shift due to the test brazing. Two halfcell pieces were brazed as shown in Fig. 5. The frequency was corrected to that of the vacuum condition at the operating temperature of $27^{\circ} \mathrm{C}$ (see Appendix B) (unit: $\mathrm{MHz}$ ).

\begin{tabular}{lccc}
\hline \hline (Accelerating mode) & Before & After & Shift \\
\hline Frequency & $972.44^{\mathrm{a}}$ & 972.54 & 0.10 \\
$Q$ value & 8080 & 8050 & -30 \\
\hline (Coupling mode) & Before & After & Shift \\
\hline Frequency & $979.76^{\mathrm{a}, \mathrm{b}}$ & 980.47 & 0.71 \\
$Q$ value & 1340 & 5500 & 4160 \\
\hline \hline
\end{tabular}

${ }^{\mathrm{a}}$ Frequencies were not tuned.

${ }^{\mathrm{b}}$ Typical measurement error was $\pm 0.15 \mathrm{MHz}$. 


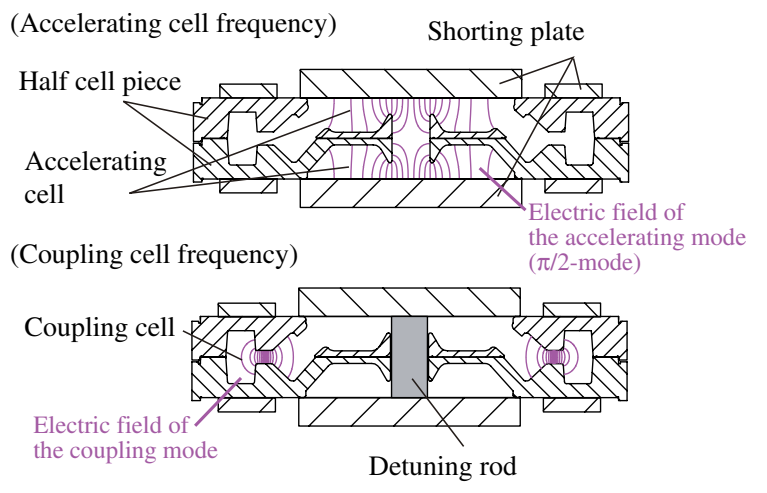

FIG. 5. Measurement setup and electric-field distribution for the normal cell frequencies. The frequencies were measured by a pair of two half-cell pieces using shorting plates. The accelerating-cell frequency was measured for the $\pi / 2$ mode. The coupling-cell frequency was evaluated from the detuning measurement by using a detuning rod placed at the beam axis. The field distributions were calculated by using SUPERFISH for the axially symmetric cells (without the coupling slots).

accelerating-mode and coupling-mode frequencies were tuned within $\pm 0.11 \mathrm{MHz}$, barely satisfying the required accuracies listed in Table III. However, it should be noted that all the frequency differences for the accelerating cells are positive, the average difference being $+0.095 \mathrm{MHz}$. This value is significantly larger than the value of $\pm 0.035 \mathrm{MHz}$ (the half of the difference between the maximum and minimum values of these differences), indicating that there is some systematic error.

TABLE V. Normal cell frequencies after the final machining vs the designed frequency (unit: $\mathrm{MHz}$ ).

\begin{tabular}{lccc}
\hline \hline Accelerating cell no. $^{\mathrm{a}}$ & Designed $^{\mathrm{b}}$ & Achieved & Difference \\
\hline (Tank 1) 3 $_{5}$ & $972.18^{\mathrm{b}}$ & 972.22 & +0.04 \\
7 & $972.18^{\mathrm{b}}$ & 972.29 & +0.11 \\
(Tank 2) 3 & $972.18^{\mathrm{b}}$ & 972.28 & +0.10 \\
5 & $972.18^{\mathrm{b}}$ & 972.29 & +0.11 \\
7 & $972.18^{\mathrm{b}}$ & 972.29 & +0.11 \\
Average & $972.18^{\mathrm{b}}$ & 972.28 & +0.10 \\
\hline Coupling cell no. ${ }^{\mathrm{a}}$ & & & +0.095 \\
\hline (Tank 1) 2 & Designed & Achieved & Difference \\
4 & 971.30 & 971.41 & +0.11 \\
6 & 971.30 & 971.35 & +0.05 \\
8 & 971.30 & 971.35 & +0.05 \\
(Tank 2) 2 & 971.30 & 971.31 & +0.01 \\
4 & 971.30 & 971.39 & +0.09 \\
6 & 971.30 & 971.34 & +0.04 \\
8 & 971.30 & 971.35 & +0.05 \\
Average & 971.30 & 971.29 & -0.01 \\
\hline \hline
\end{tabular}

${ }^{\mathrm{a}}$ The cell numbering is shown in Figs. 6(a) and 7(a).

${ }^{\mathrm{b}}$ The original designed frequency was $971.94 \mathrm{MHz}$, as described in the text. This value was increased to $972.18 \mathrm{MHz}$ (see Appendix C).
In order to clarify the reason for the systematic error, $d f / d r$ values for the accelerating cell are listed in Table VI. It can be seen that the value of $d f / d r$ in step (ii) decreased by $0.14 \mathrm{MHz} / \mathrm{mm}$ from that in step (i). As a result, the average accelerating-cell frequency became higher. This frequency offset of $0.095 \mathrm{MHz}$ is mainly attributed to the error in the value of $d f / d r$. Thus, it will be possible to reduce the frequency-tuning error by determining the value of $d f / d r$ more accurately and/or by minimizing the final machining radial depth $\Delta r$.

The difference of $0.14 \mathrm{MHz} / \mathrm{mm}$ between the values of $d f / d r$ in steps (i) and (ii) is hard to understand. The accuracies in the frequency measurement and radius machining are $\pm 0.03 \mathrm{MHz}$ and $\pm 0.01 \mathrm{~mm}$, respectively. The error in the value of $d f / d r$ is then dominated by the measurement error, resulting in an error of $\pm 0.09 \mathrm{MHz} / \mathrm{mm}$ (obtained by $0.03 / 0.329$ ) in the value of $d f / d r$ in step (i) $(1.28 \mathrm{MHz} / \mathrm{mm})$ (the contribution of the machining error, i.e., $\pm 0.01 \mathrm{~mm}$, corresponds to an error of $\pm 0.04 \mathrm{MHz} / \mathrm{mm})$. The difference of $0.14 \mathrm{MHz} / \mathrm{mm}$ in the value of $d f / d r$ is significantly larger than the contribution of the frequency-measurement errors to the value of $d f / d r$, i.e., $\pm 0.09 \mathrm{MHz} / \mathrm{mm}$. One possible reason for this big difference is the deformation of the cells during the machining for frequency tuning. More care should be taken to minimize the deformation and the value of $d f / d r$ should also be determined more carefully.

\section{Frequency shift due to brazing}

Figures 6 and 7 show the frequency-tuning results before the brazing and the variations in the cell frequencies due to the brazing process. First, both the end-cell parts were brazed [the brazed parts are surrounded by dotted red lines in Figs. 6(b) and 7(b)], and the frequencies were then measured for the combination of both the parts. Figures 6 (b) and 7(b) indicate that the frequencies of the end-cell parts varied by -0.09 and $0.10 \mathrm{MHz}$, respectively, during the first brazing. After the final brazing, the acceleratingmode and coupling-mode frequencies were measured for the entire accelerating tank. Here, the accelerating-mode frequency $f_{a}$ was the $\pi / 2$-mode frequency, while the coupling-mode frequency $f_{c}$ was evaluated from the following equation:

TABLE VI. Coefficient $d f / d r(\mathrm{MHz} / \mathrm{mm})$ for the accelerating cell.

\begin{tabular}{lcccc}
\hline \hline Tuning step & $\Delta f(\mathrm{MHz})$ & $\Delta r(\mathrm{~mm})$ & $d f / d r$ & Used $d f / d r$ \\
\hline I & $0.420^{\mathrm{a}}$ & $0.329^{\mathrm{a}}$ & $1.28^{\mathrm{a}} \pm 0.03^{\mathrm{b}}$ & $1.1^{\mathrm{c}}$ \\
ii & $0.666^{\mathrm{a}}$ & $0.584^{\mathrm{a}}$ & $1.14^{\mathrm{a}} \pm 0.08^{\mathrm{b}}$ & $1.3^{\mathrm{d}}$ \\
\hline \hline
\end{tabular}

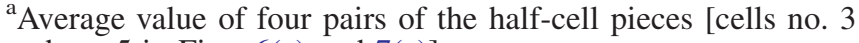
and no. 5 in Figs. 6(a) and 7(a)].

${ }^{\mathrm{b}}$ The half of the difference between the maximum and minimum values.

${ }^{\mathrm{c}}$ Evaluated by machining the prototype half-cell pieces.

${ }^{\mathrm{d}}$ Obtained from step (i), 1.28 rounded to 1.3 . 


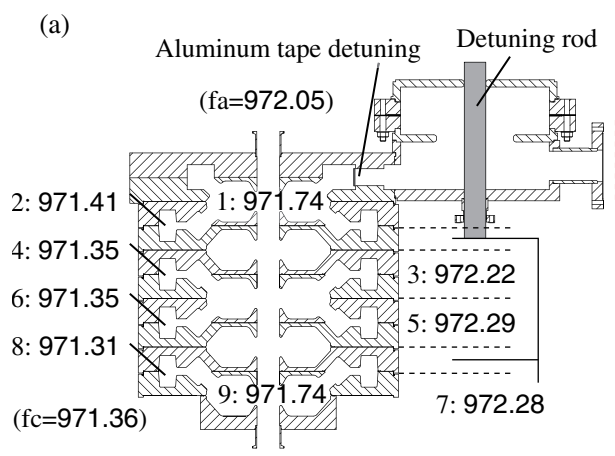

(b)

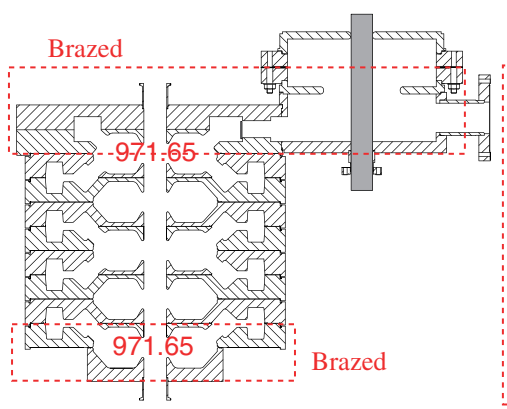

(c) Detuning rod

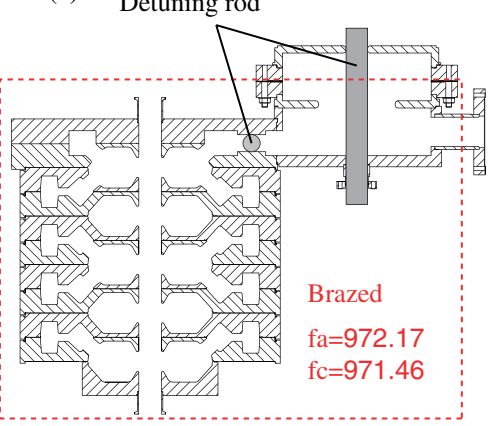

FIG. 6. Variations in the cell frequencies for accelerating tank 1 due to the brazing process. The dotted red lines surround the brazed parts. The bridge tank and side-coupling cell are detuned with a detuning rod or an aluminum tape with a width of $4 \mathrm{~mm}$. (a) The cell frequencies just after frequency tuning with an ultraprecision lathe. The accelerating-mode frequency $(f a)$ and coupling-mode frequency $(f c)$ are evaluated by averaging the accelerating cells and the coupling cells, respectively. (b) The cell frequencies just after the first brazing. (c) The accelerating-mode and coupling-mode frequencies after the final brazing.

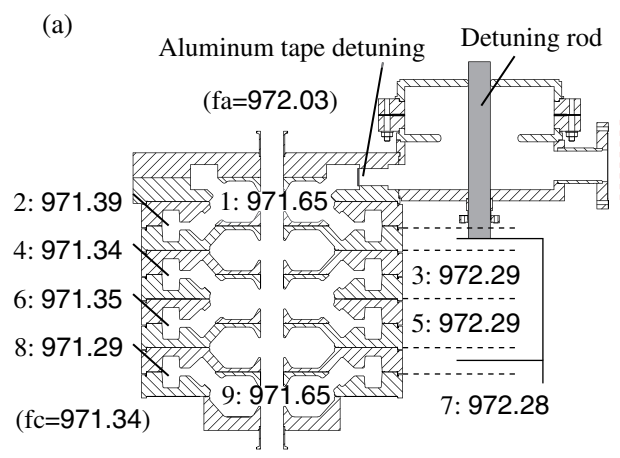

(b)

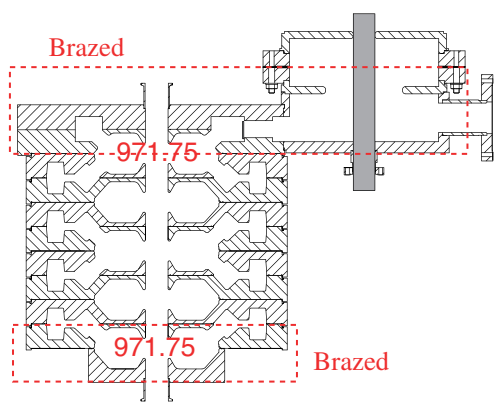

(c) Detuning rod

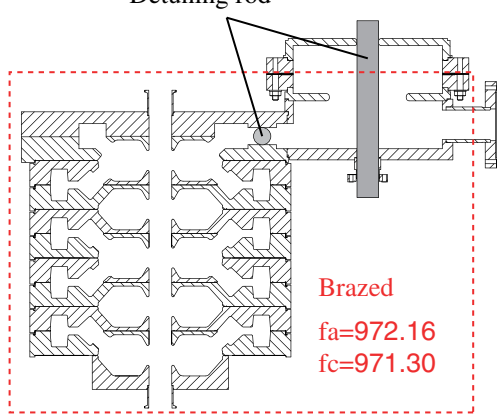

FIG. 7. Variation in the cell frequencies of accelerating tank 2 due to the brazing process.

$$
f_{c}=f_{u}+f_{l}-f_{a}
$$

where $f_{u}$ and $f_{l}$ are the higher and lower modes nearest to the $\pi / 2$ mode, respectively [10].

Table VII lists the frequency shifts due to the brazing process. It can be seen that the average frequency shift for the accelerating mode was $0.13 \mathrm{MHz}$, which is close to the expected frequency shift of $0.10 \mathrm{MHz}$ based on the result obtained from the test brazing of the two half-cell pieces. In contrast, the average frequency shift for the coupling mode was $0.03 \mathrm{MHz}$, which is considerably lower than the expected shift of $0.71 \mathrm{MHz}$.

This discrepancy can be attributed to the measurement error in the coupling-mode frequency during the test brazing. In this regard, it should be noted that the $Q$ value of the coupling cell as measured before the test brazing was significantly lower than that of the coupling cell after the brazing, as listed in Table IV. This indicates that the rf contact between the two half-cell pieces was not stable, which possibly gave rise to the error in the frequency measurement.

It can be seen from Table VII that the frequency-shift difference between tanks 1 and 2 for the accelerating mode is $0.01 \mathrm{MHz}$ and that for the coupling mode is $0.14 \mathrm{MHz}$. Each of these values can be considered as a measure of the reproducibility of the frequency shift. The reproducibility for the coupling mode is much worse than that for the accelerating mode. The frequency shift for the coupling mode should be carefully examined in future.

The accelerating-mode frequencies for tanks 1 and 2 were higher than the designed frequency of $972.04 \mathrm{MHz}$ by 0.13 and $0.12 \mathrm{MHz}$, respectively. The corresponding coupling-mode frequencies were lower than the designed frequency of $972.00 \mathrm{MHz}$ by 0.54 and $0.70 \mathrm{MHz}$, respectively [see Figs. 6(c) and 7(c)]. These frequency-tuning accuracies were not sufficient for an accelerating module with a large number of cells, as shown in Appendix A. However, they are sufficient for a buncher module with a small number of cells. Therefore, such a buncher module will be put to practical use.

\section{LOW-LEVEL RF MEASUREMENT}

The electric-field distribution was measured by the bead-pull method. The frequency perturbation was derived from the phase shift $\arg \left(S_{21}\right)$ at the unperturbed resonant frequency, at which the conversion coefficient for phase to frequency was measured beforehand. The bead was pulled by a pulsed motor at a constant speed of typically 
TABLE VII. Frequency shift due to the brazing process (unit: $\mathrm{MHz})$.

\begin{tabular}{lcccc}
\hline \hline $\begin{array}{l}\text { (Accelerating mode) } \\
\text { Tank no. }\end{array}$ & Before & After & Shift & Expected \\
\hline 1 & $972.05^{\mathrm{a}}$ & 972.17 & +0.12 & \\
2 & $972.03^{\mathrm{a}}$ & 972.16 & +0.13 & \\
Average & & & +0.13 & $+0.10^{\mathrm{b}}$ \\
\hline (Coupling mode) & & & & \\
Tank no. & Before & After & Shift & Expected \\
\hline 1 & $971.36^{\mathrm{c}}$ & 971.46 & +0.10 & \\
2 & $971.34^{\mathrm{c}}$ & 971.30 & -0.04 & \\
Average & & & +0.03 & $+0.71^{\mathrm{b}}$ \\
\hline \hline
\end{tabular}

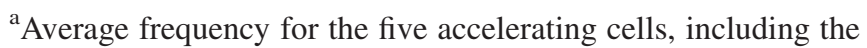
end-cell parts [see Figs. 6(a) and 7(a)].

${ }^{\mathrm{b}}$ Expected frequency shifts were determined from the test-cell brazing (Table IV).

${ }^{c}$ Averaged frequency for the four coupling cells [see Figs. 6(a) and $7(\mathrm{a})]$.

$0.87 \mathrm{~mm} / \mathrm{s}$, and a vector network analyzer measured the phase shift continuously.

Figure 8 shows the frequency perturbation thus measured, when the cavity was tuned to the operating frequency with a tuning plunger. The wire diameter was $0.165 \mathrm{~mm}$ and the bead diameter was $3 \mathrm{~mm}$ (the diameter of the beam bore was $40 \mathrm{~mm}$ ). The peak frequency shift was $5.3 \mathrm{kHz}$ while the baseline fluctuation was $\pm 0.013 \mathrm{kHz}$, which was evaluated as the standard deviation at points $\beta \lambda / 2$ apart outside the cavity. This measurement was performed under a nitrogen-gas flow to stabilize the measured data. In Fig. 8, the flatness defined by $\left(x_{\max }-\right.$ $\left.x_{\min }\right) / \bar{x}$ is shown for tank 1 , tank 2 , and the entire module, where $x_{\max }, x_{\min }$, and $\bar{x}$ are the maximum, minimum, and average values of the electric-field amplitude (square root of the frequency shift), respectively.

A flatness of $0.7 \%$ was calculated from the coupled resonator model, using the measured frequencies for this buncher module. This value is in reasonable agreement with the measured values.

The average electric-field amplitude for tank 2 (the average of four peaks except for the end-cell one) was $0.34 \%$ higher than that for tank 1 . It is considered that this difference resulted from some errors in the coupling factors at the two connecting parts between the accelerating and bridge tanks. The total flatness for the entire buncher module (except for both end cells) was $1.4 \%$.

TABLE VIII. Cavity $Q$ value and $R / Q$.

\begin{tabular}{lccc}
\hline \hline & Calculated $^{\mathrm{a}}$ & Measured & $\%$ \\
\hline$Q$ value & 18150 & 17720 & 97.6 \\
$R / Q$ & $1.96 \times 10^{3} \Omega$ & $1.98 \pm 0.04^{\mathrm{b}} \times 10^{3} \Omega$ & $101.0 \pm 2.1^{\mathrm{b}}$ \\
\hline \hline
\end{tabular}

${ }^{a}$ The calculation is detailed in Appendix D.

${ }^{\mathrm{b}}$ This error was evaluated via shifting the zero axis by $\sigma=$ $\pm 0.013 \mathrm{kHz}$ (see Fig. 8) for the electric-field integration.

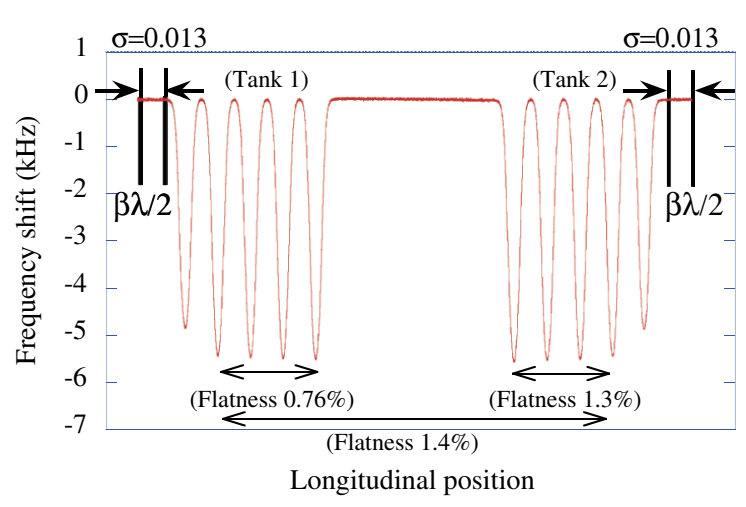

FIG. 8. Frequency shift measured with the bead-pull method. The flatness is also shown. The total flatness for the two tanks is $1.4 \%$.

This value is acceptable for the practical use of the buncher.

Figure 9 shows the dispersion curve of the cavity, which was tuned to the operating frequency with the tuning plungers. These resonant modes were obtained from $S_{21}$ measurement using the two antennas attached at both end cells (at the side of the vacuum manifold). This figure only shows the resonant modes could be measured. Since this cavity consists of 25 cells in total, the 13th mode corresponds to $\pi / 2$ mode (accelerating mode).

Table VIII shows the calculated and measured values of the cavity $Q$ value and $R / Q$. The calculated values, which are scaled from the results obtained for the normal cell (biperiodic structure), do not include the effect of the end cell. In Fig. 8, the electric field for the end-cell part is significantly smaller than those for the other cells. The values of $R / Q$ listed in Table VIII, therefore, include correction for both the end cells to compare these values to the calculated value. The $R / Q$ value obtained by the integration of the electric field for this end cell was substituted by the average value of $R / Q$ for the other four cells in the same tank. This buncher module achieved an $R / Q$ value that was $101.0 \%$ of the calculated value.

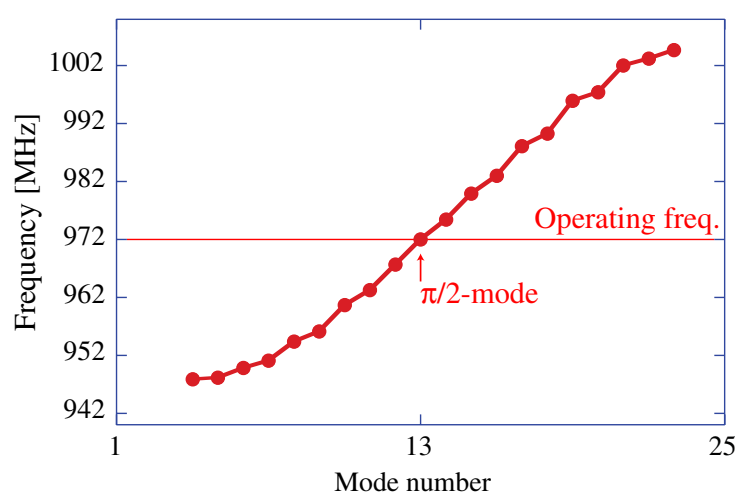

FIG. 9. Dispersion curve obtained from $S_{21}$ measurement using the two antennas attached at both end cells (at the side of the vacuum manifold). 


\section{HIGH-POWER TEST}

\section{A. Measurement setup}

Figure 10 shows a schematic view of the monitoring system for the cavity performance. Figure 11 shows a picture of the ACS buncher module installed in the highpower-test area. The following four parameters were monitored: the input power $\left(P_{\text {in }}\right)$, reflection power $\left(P_{\mathrm{r}}\right)$, and electric fields for the two end cells $\left(E_{\text {cav }}\right)$. The two fields were measured to determine the unbalance between the two accelerating tanks. Independently, the flow of and temperature rise in the cooling water was recorded to evaluate the power dissipation by using calorimetry. These quantities were measured with a turbine flow meter and precise thermometer, respectively.

For efficient vacuum pumping during the conditioning stage, two ion pumps with capacities of $400 \mathrm{~L} / \mathrm{s}$ were installed at both ends of the accelerating tank (see Fig. 4). The vacuum pressure at the center of the bridge tank was measured with a Bayard-Alpert gauge. In addition, the pressures in the two ion pumps were monitored by the currents in the two ion pumps.

The rf power was turned off at a switching speed of a few microseconds at a certain value of the reflected power for protecting the cavity and input window from excessive damage. The rf power was switched off at a vacuum pressure of $1 \times 10^{-4} \mathrm{~Pa}$.

\section{B. Conditioning history}

A cavity dissipation power of $360 \mathrm{~kW}$ is required to generate the designed accelerating field of $4.1 \mathrm{MV} / \mathrm{m}$, since the measured shunt impedance is $40.1 \mathrm{M} \Omega / \mathrm{m}$ with a cavity length of $0.857 \mathrm{~m}$. The stable and reliable operation of a cavity requires its conditioning beyond the operational power for a fair amount of time. A margin of 30\% (in an accelerating field) for the maximum power dissipation of $600 \mathrm{~kW}$ was included for this conditioning.

The conditioning history of the present ACS cavity is shown in Fig. 12. At first, the peak power was increased with a fixed pulse width of $20 \mu \mathrm{s}$, which is much shorter than that for the designed one. The repetition was main-

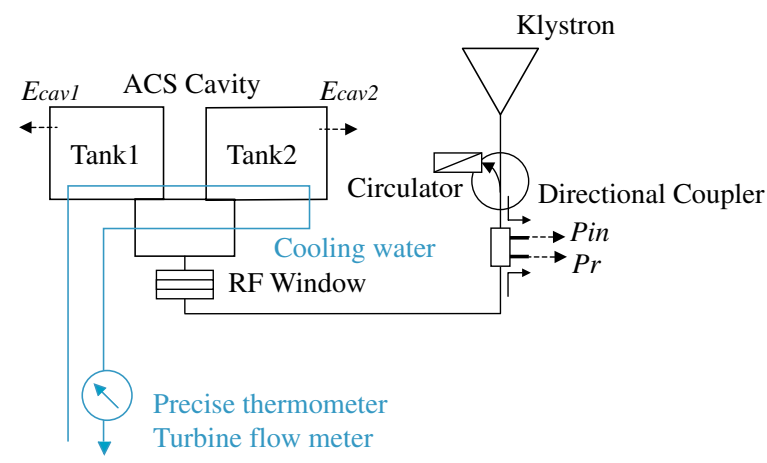

FIG. 10. Schematic view of the monitoring system for the cavity performance.

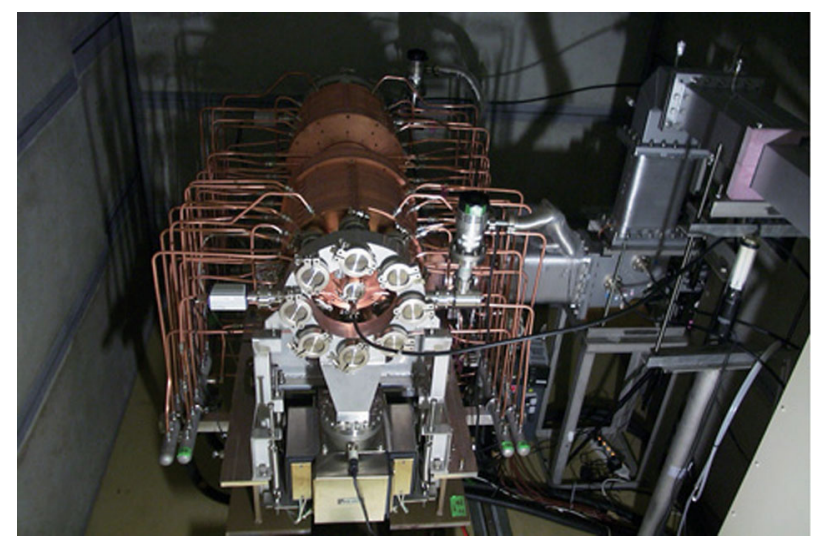

FIG. 11. ACS buncher module installed in the high-power-test area.

tained at $50 \mathrm{~Hz}$ throughout this test. It took 15 hours to achieve the peak power of $600 \mathrm{~kW}$. In the next step, the pulse length was increased from 20 to $600 \mu$ s at the fixed peak power of $600 \mathrm{~kW}$. After 35 hours from the start of the conditioning, we achieved a pulse width of $600 \mu \mathrm{s}$ with a peak power of $600 \mathrm{~kW}$ and a repetition of $50 \mathrm{~Hz}$.

From a practical viewpoint, this conditioning time was within the acceptable range. It can be checked whether this conditioning time is reasonable from Table IX that lists other examples of conditioning histories with the same pulse lengths and same repetition. It can be seen that the conditioning time required for the ACS is 1.5 times that required for the separated-type drift tube linacs (SDTLs) to be conditioned to the same surface electric field. However, the ACS is loaded with the coupling cells, which do not exist for the SDTLs. Furthermore, the conditioning procedure for the ACS (when to increase the input power) was different from that for the SDTLs. As described in III A 1, the electric-field strength comparable to or lower than the Kilpatrick field $E_{k}$ was chosen for the peak surface field $E_{\mathrm{sp}}$ of the ACS in the cavity design process. Partly due to the conservative design, the cavity could be conditioned without any issues.

Figure 12 shows the history of the vacuum pressure under the high-power operation. The pressure denoted by VAC is the pressure at the center of the bridge cavity, while those denoted by IP1 and IP2 are the pressures monitored by the currents in the two ion pumps. When the input power was increased, the peak power and pulse length were kept constant until the vacuum pressure lowered down to $5 \times 10^{-5} \mathrm{~Pa}$ or less, which is much lower than the interlock pressure of $1 \times 10^{-4} \mathrm{~Pa}$.

At a cooling-water flow of $100 \mathrm{~L} / \min \left(27^{\circ} \mathrm{C}\right)$ and an input power of $600 \mathrm{~kW}$ (duty factor: $3 \%$ ), the temperature rise at the cavity surface was in the range $3-4^{\circ} \mathrm{C}$ and the increase of the water temperature was $2.4^{\circ} \mathrm{C}$, which is smaller than the calculated value of $2.6^{\circ} \mathrm{C}$. This error is partly due to the heat loss to the environment. However, after this first conditioning, the cavity was also conditioned 

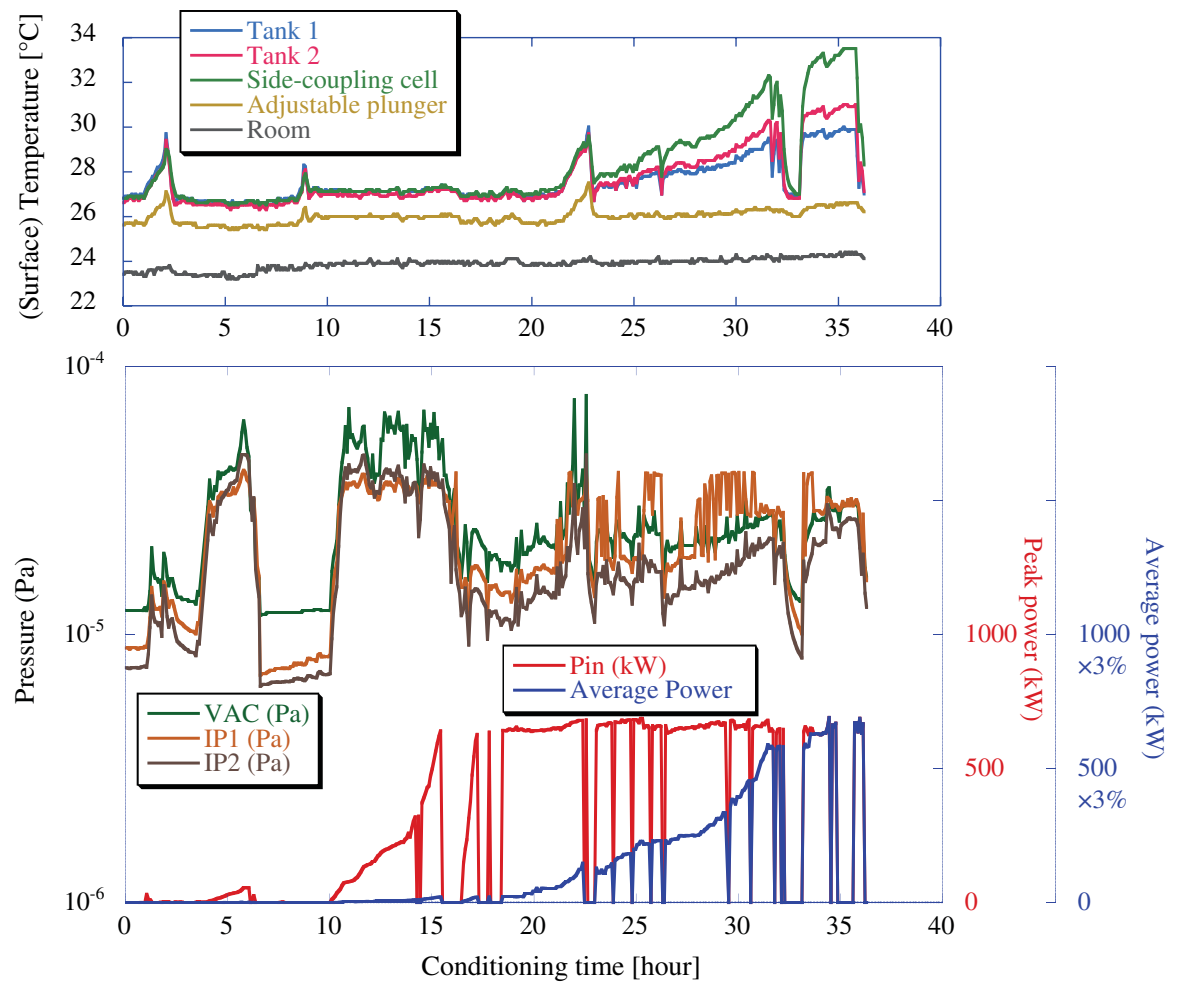

FIG. 12. Temperature (top) and conditioning (bottom) history of the ACS buncher module. The temperature rises were monitored by resistance thermometers (Pt100). $P_{\text {in }}$ is the input power, as shown in Fig. 10. This graph shows the data points per five minutes. Thus, a short downtime does not appear in this graph. The pressure denoted by VAC is the pressure at the center of the bridge cavity, while those denoted by IP1 and IP2 are the pressures monitored by the currents in the two ion pumps.

separately to increase the temperature raise of the cooling water up to $2.7^{\circ} \mathrm{C}$ in order to ensure the minimum input power of $600 \mathrm{~kW}$. The thermal detuning was $-0.11 \mathrm{MHz}$, which is much smaller than the tunable limits of $\pm 0.5 \mathrm{MHz}$ with the adjustable plungers. Here, the resonant frequency as a function of the adjustable plunger positions is shown in Fig. 13. This detuning was in good agreement

TABLE IX. Conditioning time and power levels for SDTL [11] vs ACS.

\begin{tabular}{lccccc}
\hline \hline & $\begin{array}{c}\text { Time } \\
(\mathrm{h})\end{array}$ & $\begin{array}{c}\text { Power } \\
(\mathrm{kW})\end{array}$ & $\begin{array}{c}E_{0}{ }^{\mathrm{a}} \\
(\mathrm{MV} / \mathrm{m})\end{array}$ & $\begin{array}{c}E_{\mathrm{sp}}{ }^{\mathrm{b}} \\
(\mathrm{MV} / \mathrm{m})\end{array}$ & $E_{\mathrm{sp}} / E_{k}{ }^{\mathrm{c}}$ \\
\hline SDTL1 $^{\mathrm{d}}$ & 18 & 200 & 2.7 & 25.1 & 1.4 \\
& 20 & 300 & 3.3 & 30.7 & 1.7 \\
& 25 & 500 & 4.3 & 39.7 & 2.2 \\
SDTL2 $^{\mathrm{d}}$ & 23 & 380 & 3.7 & 34.6 & 1.9 \\
& 33 & 500 & 4.3 & 39.7 & 2.2 \\
ACS $^{\mathrm{e}}$ & 33 & 600 & 5.3 & 29.6 & 1.0 \\
\hline \hline
\end{tabular}

${ }^{\mathrm{a}}$ Accelerating field.

${ }^{\mathrm{b}}$ Maximum surface field.

${ }^{\mathrm{c}}$ Kilpatrick field $\left(E_{k}=17.8 \mathrm{MV} / \mathrm{m}\right.$ for $324 \mathrm{MHz}$ and $E_{k}=$ $28.3 \mathrm{MV} / \mathrm{m}$ for $972 \mathrm{MHz}$ ).

${ }^{\mathrm{d}}$ Operated at $324 \mathrm{MHz}$. Five accelerating gaps with a length of $1.5 \mathrm{~m}$.

e Operated at $972 \mathrm{MHz}$. Ten accelerating cells with a length of $0.9 \mathrm{~m}$. with the calculated value of $-0.12 \mathrm{MHz}$, which is scaled from the result obtained in Ref. [9].

It can be seen from Fig. 12 that the pressures ranged from $2 \times 10^{-5}$ to $3 \times 10^{-5} \mathrm{~Pa}$ with the input power during the conditioning. This pressure, which was sufficiently low for the high-power conditioning, is 1 order of magnitude higher than the required value of $4 \times 10^{-6} \mathrm{~Pa}$. This value is required to prevent the beam loss for the $\mathrm{H}^{-}$beams becoming higher than $0.1 \mathrm{~W} / \mathrm{m}$, which results from electron stripping by the residual gas. It appears that this high

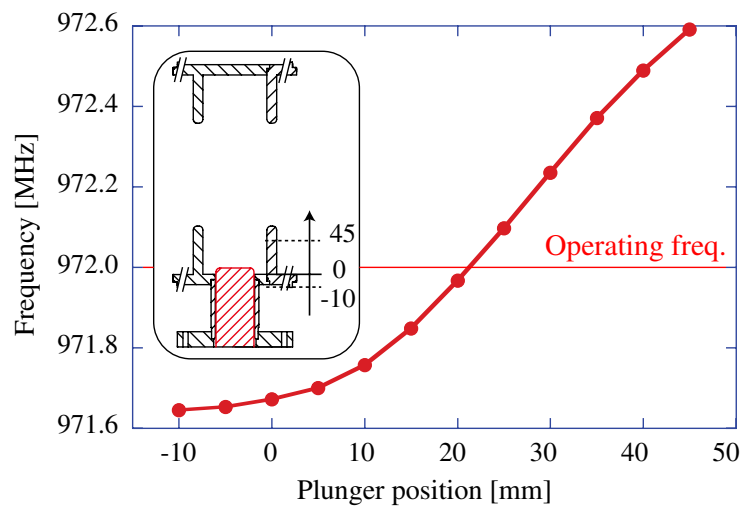

FIG. 13. Resonant frequency as a function of the adjustable plunger positions (the three plungers are moved simultaneously). 
pressure is mainly due to the Viton O-rings between the accelerating tank and vacuum manifold. In future, these Viton O-rings will be replaced by metal gaskets.

The surface of the rf window was observed with a CCD camera from the view port in the bridge tank. Its temperature was measured with an infrared thermography camera. Neither a spark in the rf window nor a sharp rise in the temperature, which could be caused by multipactoring, was observed throughout this conditioning. This is reasonable since the rf window used in this study was designed and developed for the high average power in the case of a full-length ACS cavity (a pair of 17 accelerating cells).

\section{SUMMARY}

The purpose of the present study is to demonstrate the feasibility of achieving the required performance from a newly designed ACS.

As mentioned in the Introduction, the axially symmetric structure of the ACS makes it possible to use an ultraprecision lathe except for machining the coupling slots. On the other hand, the accelerating cell of the ACS is surrounded by a coupling cell, making it difficult to tune the accelerating-cell frequency from the outside. For this reason, all the cell frequencies were tuned by ultraprecision machining before assembling, taking into account the frequency shift due to brazing.

The accelerating- and coupling-cell frequencies could be tuned within $\pm 0.11 \mathrm{MHz}$, as listed in Table V. This value is much smaller than the tolerance for an ACS buncher module with a small number of cells. However, this value barely satisfies the required accuracy of $\pm 0.1 \mathrm{MHz}$ for the ACS-accelerating module with a large number of cells. The accuracy for the coefficient $d f / d r$ has to be improved for reducing the tuning error. For that purpose, the final machining radial depth will be decreased in future.

As can be seen from Table VII, the frequency shifts due to brazing were scattered, but the reproducibilities (the difference between tanks 1 and 2) were within the limit of $\pm 0.1 \mathrm{MHz}$, which is required for the frequency-tuning accuracy. After assembling, the accelerating-mode frequencies for tank no. 1 and no. 2 were higher than the design frequency of $972.04 \mathrm{MHz}$ by 0.13 and $0.12 \mathrm{MHz}$, respectively. The corresponding coupling-mode frequencies were lower than the design frequency of $972 \mathrm{MHz}$ by 0.54 and $0.70 \mathrm{MHz}$, respectively. These discrepancies were mainly due to the poor reproducibility of the frequency shift due to brazing. These values were sufficient for the present buncher module with a small number of cells, but not for an accelerating module with a large number of cells. Therefore, we need to accumulate the experimental data for the frequency shift due to brazing.

From the bead-pull measurement, the value of $R / Q$ was in agreement with the calculated values. The present cavity was successfully conditioned up to $600 \mathrm{~kW}$, which corresponds to an accelerating field that is higher than the designed field of $4.1 \mathrm{MV} / \mathrm{m}$ by $30 \%$. The conditioning time for the present cavity was comparable to those for other structures.

The results obtained in the present study show the following: (i) The newly designed J-PARC ACS could be fabricated by brazing. (ii) The accelerating-cell frequencies could be properly tuned by ultraprecision machining (some issues regarding the coupling-cell tuning still remain). (iii) The generated accelerating field was higher than the designed field by $30 \%$.

The results obtained in this study provide us with a basis for fabricating and testing a full-length ACS cavity (a pair of 17 accelerating cells).

\section{ACKNOWLEDGMENTS}

We would like to thank the members of the J-PARC linac group for their fruitful comments and support. Special thanks are due to the staff of Mitsubishi Heavy Industries, Ltd. for manufacturing the ACS cavity.

\section{APPENDIX A: EVALUATION OF THE FIELD FLATNESS WITH THE COUPLED-RESONATOR- MODEL ANALYSIS}

The cell-to-cell coupling factors for the ACS buncher module are shown in Fig. 14. The coupling factor for the bridge tank is designed to be twice as large as that for the accelerating tank. The coupling factor $k$ is 0.06 for the ACS buncher module.

Here, the flatness is defined as

$$
\frac{x_{\max }-x_{\min }}{\bar{x}},
$$

where $x_{\max }, x_{\min }$, and $\bar{x}$ are the maximum, minimum, and average values of the electric-field amplitude (square root of the frequency shift), respectively. If all the frequency deviations for the accelerating and coupling cells are given by $\Delta f_{a}$ and $\Delta f_{c}$, respectively, the coupled-resonator model [12] provides us with the following relation [13]:

$$
\frac{x_{\max }-x_{\min }}{\bar{x}}=8 N(N-1) \frac{\Delta f_{a}}{f_{\text {pass }}} \frac{\Delta f_{c}}{f_{\text {pass }}},
$$

where $f_{\text {pass }}$ is the passband width, and $N$ is the number of the accelerating cells of a tank. In the present case of $f_{\text {pass }}=0.06 \times 972 \mathrm{MHz}$ and $N=17$, we require $\Delta f_{a}<$ $0.125 \mathrm{MHz}$ and $\Delta f_{c}<0.125 \mathrm{MHz}$ for the flatness to be less than $1 \%$. Therefore, we set a tolerance of $0.1 \mathrm{MHz}$ for both $\Delta f_{a}$ and $\Delta f_{c}$ with some margins.

\section{APPENDIX B: CORRECTION OF THE FREQUENCY SHIFT DUE TO THE DIELECTRIC CONSTANT AND THERMAL EXPANSION}

In this report, all the measured frequencies were corrected to those of the vacuum condition at $27^{\circ} \mathrm{C}$ (operating 


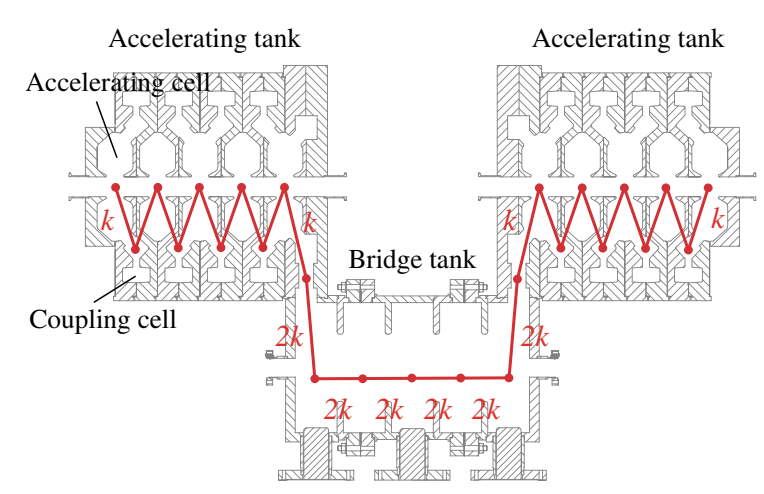

FIG. 14. Cell-to-cell coupling factors for the ACS buncher module. The coupling factor for the bridge tank is designed to be twice as large as that for the accelerating tank.

temperature) by using the air temperature $T$, cell or cavity temperature $T_{\text {cav }}$, relative humidity $\phi(\%)$, and barometric pressure $P(\mathrm{~Pa})$. In the following equations, unless otherwise noted, all the temperatures are given in degrees Celsius.

The vapor pressure of saturated water $P_{w}$ in air is evaluated by the following relation:

$$
P_{w}=1124.7-25.52 T+4.2999 T^{2}(\mathrm{~Pa}) .
$$

This equation was obtained by using the polynomial approximation for the vapor pressures of saturated water from $15^{\circ} \mathrm{C}$ to $29^{\circ} \mathrm{C}$ every two degrees Celsius for the air temperature $T$, which is the typical temperature range of the frequency measurement for the ACS cells. There are several empirical expressions to calculate $P_{w}$, however, the result of Eq. (B1) is in agreement with that of Tetens' formula [14]: $P_{w}=6.1078 \times 10^{7.5 T /(T+237.3)}(\mathrm{hPa})$ within $\pm 0.3 \%$ in the above temperature range.

The dielectric constant of water vapor $k_{w}$ and air $k_{a}$ are given by [15]

$$
\begin{aligned}
& k_{w}=1+0.006 \frac{P / 101325}{[(T+273) / 373]^{2}}, \\
& k_{a}=1+0.000536 \frac{P / 101325}{(T+273) / 293} .
\end{aligned}
$$

The total dielectric constant $k_{e}$ can be obtained by the weighting average by the partial pressures as follows:

$$
k_{e}=k_{w} \frac{P_{w} \phi / 100}{P}+k_{a}\left(1-\frac{P_{w} \phi / 100}{P}\right) .
$$

For a measured frequency in air $f_{\text {air }}$, the frequency in vacuum $f_{\text {vac }}$ is given by

$$
f_{\mathrm{vac}}=f_{\mathrm{air}} \sqrt{k_{e}} .
$$

Here, the total dielectric constant also can be evaluated by the following equation [16]: a) Measurement of the cell No.9

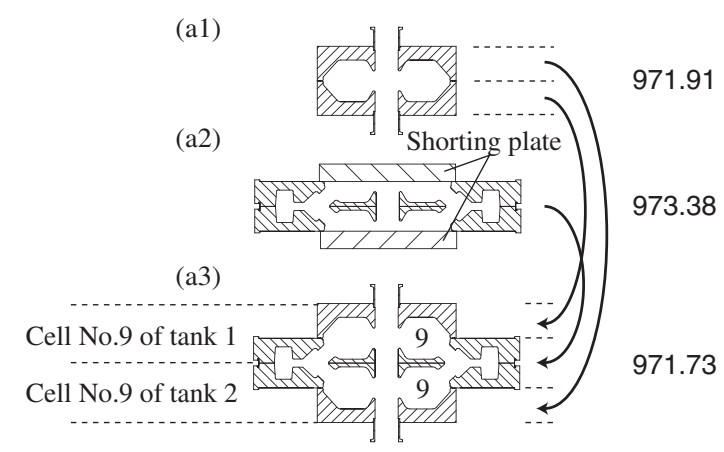

b) Measurement of the cell No.1 and No.9

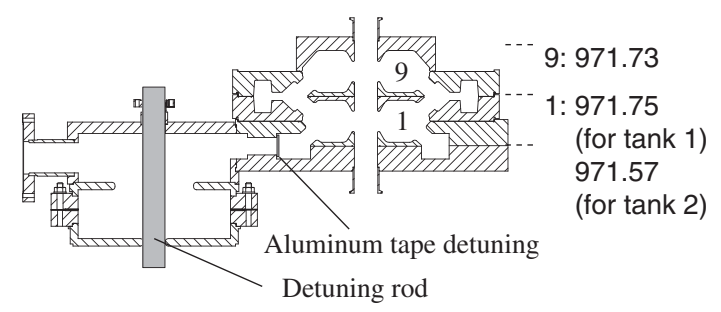

FIG. 15. Measurement setup for the end cells (no. 1 and no. 9). The cell numbering is shown in Figs. 6(a) and 7(a). (a) Measurement procedure for the two no. 9 cells. (b) Cell no. 1 and no. 9 are stacked to measure their frequencies. Only the average value was measured.

$$
k_{e}=1+0.00021 \frac{P_{a}}{T}+0.00018\left(1+\frac{5580}{T}\right) \frac{P_{w}}{T},
$$

where $T$ is the absolute temperature, $P_{a}$ and $P_{w}$ are partial pressures of air and water vapor in millimeters of mercury. If $k_{e}$ is evaluated by Eq. (B6), the result of Eq. (B5) varies by less than $0.01 \mathrm{MHz}$ for $f_{\text {air }}=972 \mathrm{MHz}$ in the above temperature range.

The corrected frequency of vacuum condition at $27^{\circ} \mathrm{C}$ is given by

$$
f_{\text {vac }, 27^{\circ} \mathrm{C}}=f_{\text {vac }}\left[1+\alpha\left(T_{\text {cav }}-27\right)\right],
$$

where $\alpha$ is the linear thermal expansion coefficient. The value of $\alpha$ used here was $1.67 \times 10^{-5} 1 /{ }^{\circ} \mathrm{C}$ for the copper around the typical temperature range of the frequency measurement.

\section{APPENDIX C: FREQUENCY-TUNING RESULTS FOR THE END-CELL PARTS}

The end-cell frequencies are listed in Table X, and their measurement setup is shown in Fig. 15. It can be seen from Table $\mathrm{X}$ that the measured frequencies were lower than the designed frequency of $971.94 \mathrm{MHz}$. The reasons for this are the mistuning of cell no. 9 and the low frequencies of cell no. 1 . Since the final machining can only decrease the cell frequency, these low frequencies were compensated for by the other cells for obtaining the operating frequency of $972 \mathrm{MHz}$. 
TABLE X. End-cell frequencies vs designed frequency (unit: $\mathrm{MHz})$.

\begin{tabular}{lccc}
\hline \hline Cell no. & Designed & Measured & Difference \\
\hline (Tank 1) 1 and 9 & 971.94 & 971.74 & -0.20 \\
(Tank 2) 1 and 9 & 971.94 & 971.65 & -0.29 \\
\hline \hline
\end{tabular}

The mistuning of cell no. 9 occurred as follows. At first, we considered that the measured frequency for the setup shown in Fig. 15(a1) should be tuned to the original designed value (971.94 MHz). After that, we measured the frequency for the setup shown in Fig. 15(a3) in order to confirm that we were using the right tuning procedure. We then found that the procedure was wrong, since the frequency for the setup shown in Fig. 15(a3) was $0.92 \mathrm{MHz}$ lower than the considered value $(972.65 \mathrm{MHz}$ obtained by averaging 971.91 and $973.38 \mathrm{MHz}$ ), i.e., we tuned the two half cells to be lower by $0.92 \mathrm{MHz} \times 2$. We should have used the setup shown in Fig. 15(a3) from the beginning to tune the two half end cells by combining the frequency of the normal cell with the known frequencies [measured by the setup shown in Fig. 15(a2)]. The discrepancy is perhaps due to the asymmetry of the end cell such that the half end cell does not have the coupling slots, which the normal half cell has.

In contrast to the case of normal cells and end cell no. 9, we have no method for tuning end cell no. 1 other than machining as designed. In order to measure the frequency for end cell no. 1, we used the setup shown in Fig. 15(b). The results listed in Table $\mathrm{X}$ indicate that the frequencies for end cell no. 1 are lower than the designed frequency by 0.19 and $0.37 \mathrm{MHz}$.

The designed frequencies for the other cells were then increased from the original designed value of 971.94 to 972.18 MHz for compensating for the effect of these discrepancies. The frequency for cell no. 1 will be increased by reducing the inner radius of the accelerating cell (see Fig. 1) in the future designs.

\section{APPENDIX D: ESTIMATION OF THE $Q$-VALUE, SHUNT IMPEDANCE $Z$, AND $R / Q$ FOR THE ENTIRE MODULE WITH THE BRIDGE TANK}

The $Q$ values for the accelerating and bridge tanks are defined as

$$
Q_{a}=\omega \frac{U_{a}}{P_{a}}, \quad Q_{b}=\omega \frac{U_{b}}{P_{b}},
$$

where $\omega, U$, and $P$ are the angular frequency, stored energy, and dissipated power in the tank. The indices of "a" and "b" denote the accelerating tank and the bridge tank, respectively. In terms of these parameters, the $Q$ value for the entire module can be expressed as

$$
Q=\frac{\omega\left(U_{a}+U_{b}\right)}{P_{a}+P_{b}} .
$$

Here, the ratio of $U_{a}$ and $U_{b}$ can be evaluated as follows. The energy of one excited cell in the bridge tank is a quarter of that of an accelerating cell, since the coupling factor for the bridge tank is designed to be twice as large as that for the accelerating tank (see Fig. 14). Since the buncher module includes ten accelerating cells in the two accelerating tanks and three excited cells in the bridge tank, it gives

$$
U_{a}: U_{b}=10: \frac{3}{4} \quad U_{b}=0.075 U_{a} .
$$

Consider the entire stored energy $U$, which can be written by $U=U_{a}+U_{b}=1.075 U_{a}$. Here, the values of the shunt impedance and $R / Q$ without the bridge tank were $43.9 \mathrm{M} \Omega / \mathrm{m}$ and $2.11 \times 10^{3}$, respectively, which was calculated with MAFIA. With the bridge tank, the values of $Z$ and $R / Q$ lowered by $1 / 1.075=0.930$. Then, we get

$$
\begin{aligned}
Z & =43.9 \times 0.930=40.8(\mathrm{M} \Omega / \mathrm{m}), \\
R / Q & =2.11 \times 10^{3} \times 0.930=1.96 \times 10^{3}(\Omega) .
\end{aligned}
$$

The ratio of $P_{a}$ and $P_{b}$ can be expressed as follows:

$$
P_{a}: P_{b}=\frac{U_{a}}{Q_{a}}: \frac{U_{b}}{Q_{b}} \quad P_{b}=P_{a} \frac{U_{b}}{U_{a}} \frac{Q_{a}}{Q_{b}} .
$$

Here, the values of $Q_{a}$ and $Q_{b}$ are 17830 and 23930 , respectively, which were calculated with MAFIA and SUPERFISH. Putting these values and Eq. (D2) into Eq. (D3), we get $P_{b}=0.0559 P_{a}$. Consequently, rewriting Eq. (D1), we get

$$
Q=\frac{1+0.075}{1+0.0559} \times 17830=18150
$$

[1] Y. Yamazaki, in Proceedings of the 16th International Linac Conference, Ottawa, Canada (Atomic Energy of Canada Limited, Chalk River Laboratories, Ontario, Canada, 1992), p. 520.

[2] T. Nishikawa, S. Giordano, and D. Carter, Rev. Sci. Instrum. 37, 652 (1966).

[3] E. A. Knapp, B.C. Knapp, and J.M. Potter, Rev. Sci. Instrum. 39, 979 (1968).

[4] V. G. Andreev, V.M. Belugin, V. G. Kulman, E. A. Mirochnik, and B. M. Pirozhenko, in Proceedings of the 1972 Proton Linear Accelerator Conference, Los Alamos, New Mexico (Los Alamos Scientific Laboratory of the University of California, Los Alamos, 1972), p. 114.

[5] T. Kageyama, Y. Morozumi, K. Yoshino, and Y. Yamazaki, in Proceedings of LINAC92 (Ref. [1]), p. 456, and references therein.

[6] Y. Yamazaki, JAERI-Tech Report No. 2003-44, 2002.

[7] Y. Yamazaki, S. Anami, H. Baba, S. Fukumoto, T. Kageyama, T. Kato, M. Kihara, Y. Mori, A. Takagi, E. Takasaki, and A. Ueno, in Proceedings of the Advanced Hadron Facility Accelerator Design Workshop, Los Alamos, 1988 (Los Alamos National Laboratory, Los Alamos, 1989), p. 80, and references therein. 
[8] V. V. Paramonov, KEK Report No. 2001-14, 2001.

[9] N. Hayashizaki, V. Paramonov, and Y. Yamazaki, in Proceedings of the 21st International Linac Conference, Gyeongju, Korea, 2002 (Pohang Accelerator Laboratory, Pohang, Korea, 2002), pp. 752-754.

[10] I. V. Gonin, L. V. Kravchuk, V. V. Paramonov, G. V. Romanov, and A. I. Pedoseev, IEEE Trans. Nucl. Sci. 32, 2818 (1985).

[11] F. Naito, Y. Fukui, Z. Igarashi, T. Kato, M. Kawamura, C. Kubota, E. Takasaki, H. Tanaka, S. Yamaguchi, K. Yoshino, and T. Ito, in Proceedings of the 21st
International Linac Conference, Gyeongju, Korea, 2002 (Ref. [9]), p. 425.

[12] D. E. Nagle, E. A. Knapp, and B.C. Knapp, Rev. Sci. Instrum. 38, 1583 (1967).

[13] Y. Yamazaki, KEK Report No. 99-2, 1999.

[14] O. Tetens, Z. Geophysik 6, 297 (1930).

[15] Chronological Science Tables, edited by National Astronomical Observatory of Japan (Maruzen Co., Ltd., Tokyo, 1993), p. 531.

[16] Technique of Microwave Measurements, edited by C. G. Montgomery (McGraw-Hill, New York, 1947), p. 391. 